\title{
A CLINICAL STUDY OF PANCURONIUM*, A NEW MUSCULAR RELAXANT FOR ABDOMINAL SURGERY $\ddagger$
}

\author{
J.P. DECHÊNE, M.D., C.R.G.P.(C), R. DESHOSIERS, M.D., C.R.C.P.(C), \\ AND O’DONNELL BÉDARD, M.D.
}

Pancunonium Bromme is a new and potent neuromuscular blocking agent, synthe: sized in 1964 by Hewett and Savage. Two quaternary ammonium groups have interposed between them a typical ketosteroid chain. These two quatemary amino groups suggest a structural analogy with D-tubocurarine. The structure of the two compounds may be compared by reference to Figures 1 and 2 .

While the intensity of relaxation varies from one species of animal to another, it is generally true that the duration of action of a relaxing dose of Pancuronium is

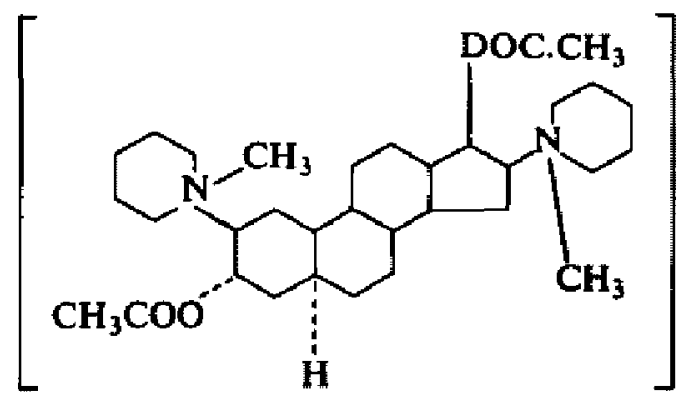

FIGURE 1

Pancturonium: (1) I steroid nucleus; (2) the nuclei are saturated; (3) the two quaternary nitrogens are substituted on the one hand by a $\mathrm{CH}_{3}$ group and the other hand by a steroid nucleus.

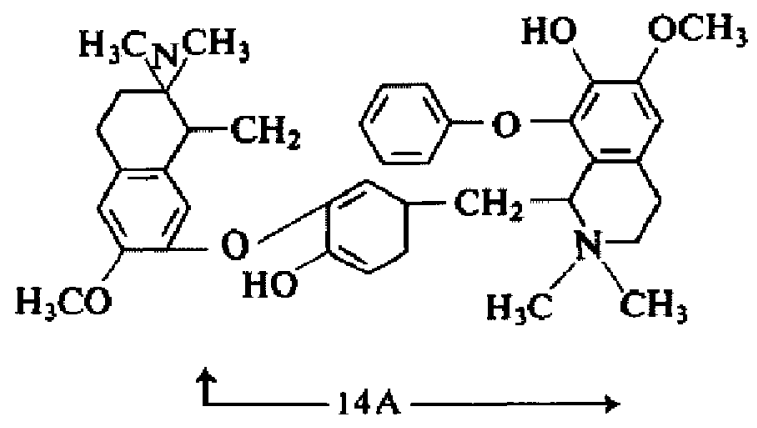

Figdre 2.

D-tubocurarine: (1) 2 isoquinoline nuclei; (2) the nuclei are non saturated; (3) the two quaternary nitrogens are substituted with two methyl groups.

\footnotetext{
- Pavulone, Organon.

†Paper presented at the annual meeting of the Canadian Anaesthetists' Society, June 29, Chatteau Frontenac, Quebec.

From Department of Anaesthesia and Resuscitation, Laval University.
} 
5 to 10 times greater than D-tubocurarine in animals and 3 to 5 times greater in man.

Unlike D-tubocurarine, Pancuronium is virtually devoid of histamine releasing activity and remarkably weaker as a neuro-ganglion blocking agent. As a primary point of interest, the authors have noted the absence of secondary effects on the cardio-vascular system, as opposed to those produced by D-tubocurarine. With Pancuronium there is little or no modification of the pulse blood pressure, venous pressure and EKG tracing. In the geriatric patient, Pancuronium is very well tolerated and is the neuro-muscular blocking agent of choice for poor risk patients. With halothane anaesthesia its minimal vagolytic-like action on the myocardium is an additional advantage. Pancuronium is also recommended in patients suffering from hepatic disease or renal insufficiency.

\section{Object of the study}

The aim of this clinical study was to determine the conditions under which Pancuronium might be used in major abdominal operations in conjunction with specifically defined methods of anaesthesia. We therefore wished to determine as precisely as possible the appropriate dosage of Pancuronium and the duration of its effect in certain types of cases.

\section{Anaesthetic technique}

The following anaesthetic procedure was used:

1. Pre-medication based on body weight and age was given one hour before the operation. It consisted of meperidine, diphenhydramine and atropine or anileridine, diphenydramine and atropine. For the poor risks, diazepam was used.

2. Anaesthesia was induced with thiopentone except in poor risk patients, when diazepam was used.

3. Endotracheal intubation was done routinely with the aid of relaxation by succinylcholine except in the poor risks when halothane only was used.

4. Anaesthesia was maintained with halothane, nitrous oxide and oxygen in a closed or semi-closed circuit using a Boyle machine and Fluotec vaporizer or Ohio machine and Vernitrol vaporizer. Respiration was controlled and a slight hyperventilation was maintained by the use of the Bird MK.IV ventilator.

5. The operative course was usually uneventful, except in certain cases when a slight tachycardia occurred due to vagolytic action of the blocking agent itself.

6. If necessary, reversal of curarization was attained by the use of neostigmine and atropine at the end of the procedure.

\section{Patients studied}

The patients who formed part of this study have been placed into five major categories, as follows:

1. Operations for malignancies of the gastrointestinal tract

2. Operations for cholelithiasis associated with simultaneous operations at other sites

3. Operations for miscellaneous disease states 33

4. Operations for peptic ulcer 23

5. Operations on the galbladder and biliary tract 110 


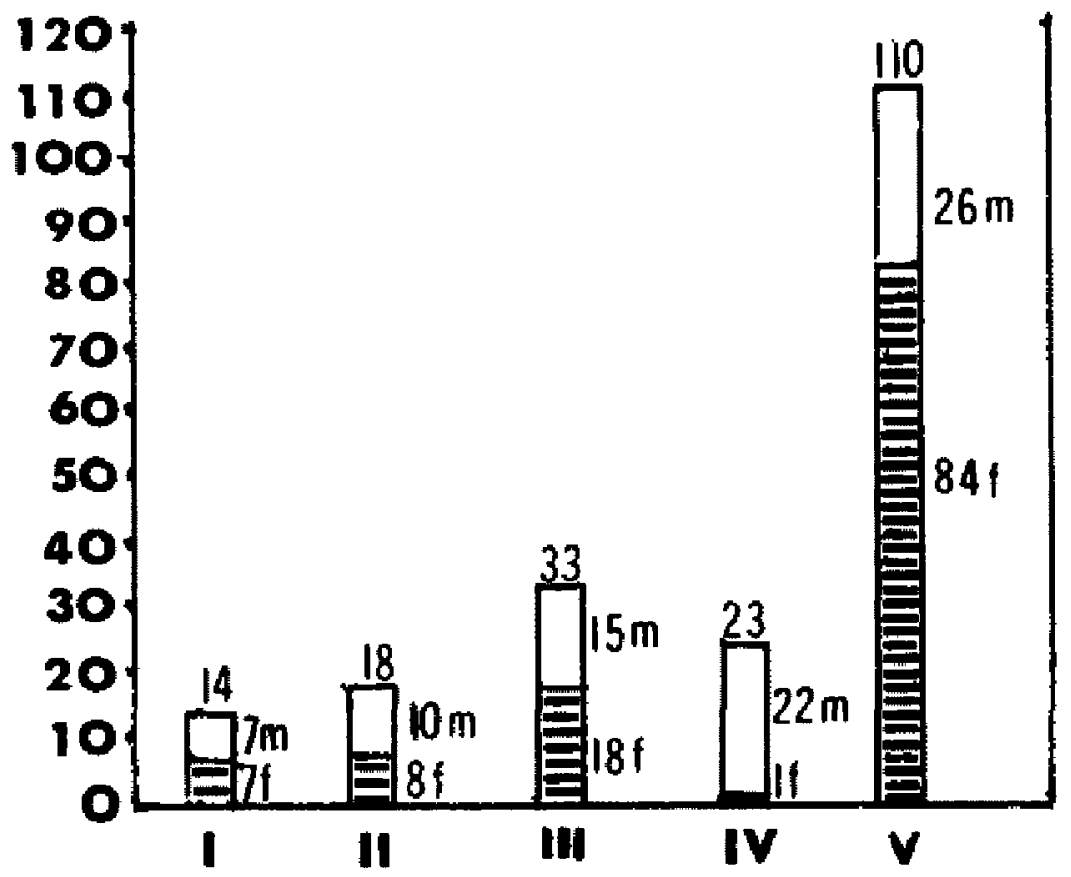

Figurs 3. Division of cases according to sex and category of disease.

Each bar = total cases in group.

White = total males in group.

Hatched = total females in group.

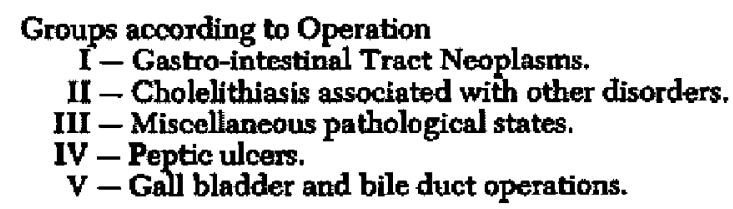

Many of the patients in each of these categories suffered from major associated pathology. The most common of these were severe anaemia, emphysema, bronchial asthma, hypertension, obesity and various miscellaneous major cardio-respiratory abnormalities.

\section{Analysis of results}

To attain the precise objective of the study a descriptive statistical analysis as well as a conclusive statistical analysis have been undertaken. This should assist in understanding of the factors which influence the duration of the initial dose of Pancuronium for different cases. Furthermore, this analysis permits an estimate of the most advantageous average dose of this new relaxant for all cases.

In this study, different dosages are considered depending upon the initial dose and the total dose. The original basic statistic on which the study is based is the division of cases according to the sex and operation (Figure 3 ).

In order to determine the relation between weight and age to the duration of the initial dose, these variables have been subdivided into three groups (Table I).

A second analysis concerns itself with the average dose of Pancuronium in milli- 
DECHENE, et al.: STUDY OF PANCURONIUM

TABLE 1

Divisions: AGE - Weight - DURATION

\begin{tabular}{ccc}
\hline Groups & Age & No. of cases \\
I (young) & from 16 to 39 years & 66 \\
II (middle aged) & from 40 to 65 years & 65 \\
II (old) & from 56 to 80 years & 67 \\
Groups & Weight & No. of cases \\
II (light) & from 82 to 126 pounds & 66 \\
III (meditum) & from 127 to 150 pounds & 66 \\
Groups & from 151 to 222 pounds & 66 \\
II (short) & Duration & No. of cases \\
II (medium) & from 30 to 89 minutes & 66 \\
III (long) & from 90 to 119 minutes & 66 \\
\hline
\end{tabular}

TABLE II

Average Dose in MG Related to Body Weight in Pounos and in Kilograms

\begin{tabular}{cccc}
\hline \hline Groups & $\mathrm{mg} / \mathrm{pds}$ & $\mathrm{mg} / \mathrm{kg}$ & No. of cases \\
\hline I & .023 & .051 & 14 \\
III & .024 & .052 & 18 \\
IV & .023 & .050 & 33 \\
V & .025 & .054 & 23 \\
& .022 & .049 & 110 \\
& .023 & .050 & 198 \\
\hline
\end{tabular}

TABLE III

DURATION

\begin{tabular}{|c|c|c|c|}
\hline Groups & $\begin{array}{l}\text { Average of } \\
\text { duration in minutes }\end{array}$ & Variation & No. of cases \\
\hline \multirow[t]{2}{*}{$\begin{array}{l}\text { II } \\
\text { III } \\
\text { IV } \\
\text { V }\end{array}$} & $\begin{array}{r}111 \\
105 \\
95 \\
97 \\
105\end{array}$ & $\begin{array}{l}25 \\
43 \\
34 \\
29 \\
25\end{array}$ & $\begin{array}{r}14 \\
18 \\
33 \\
23 \\
110\end{array}$ \\
\hline & 104 & 30 & 198 \\
\hline
\end{tabular}

grams related to body weight (in pounds and in kilograms) (Table II). In this connection we were able to establish that the doses used in this study were much less than those cited by several other authors.

Determination of the duration of action of Pancuronium is the aim of the third analysis (Table III). The average initial dose does not vary much from one group to another. The variability of the duration is reflected in the standard deviation, which in each group is quite high. One must suppose that several factors such as weight, age and the size of the initial dose determine its duration. It is interesting to note that the average duration for all cases is 104 minutes and that the average for each group differs little from that value.

The relation between body weight and the duration of action of Pancuronium is also studied (Table IV). All the other factors such as operative risk, sex, etc. 
TABLE IV

Relation of Body Weight to Duration of Actron

\begin{tabular}{|c|c|c|c|c|c|}
\hline & & $\begin{array}{c}(\text { short }) \\
\text { (I) }\end{array}$ & $\begin{array}{c}\text { Duration } \\
\text { (medium) } \\
\text { II }\end{array}$ & $\begin{array}{l}\text { (long) } \\
\text { III }\end{array}$ & Total \\
\hline $\begin{array}{l}\text { WEIGHT } \\
\text { (Light) } \\
\text { (Medium) } \\
\text { (Heavy) }\end{array}$ & $\begin{array}{r}\text { I } \\
\text { III }\end{array}$ & $\begin{array}{l}24 \\
21 \\
22\end{array}$ & $\begin{array}{l}24 \\
22 \\
23\end{array}$ & $\begin{array}{l}18 \\
22 \\
22\end{array}$ & $\begin{array}{l}66 \\
65 \\
67\end{array}$ \\
\hline Toral & & 67 & 69 & 62 & 198 \\
\hline
\end{tabular}

remaining constant, the relation between the weight and the duration of the initial dose can now be listed using the groupings previously established and listed in Table II. Statistical analysis of the data in this table reveals that there is no demonstrable relationship between the weight groupings and those relating to duration. Consequently, body weight by itself does not determine the duration of the initial dose; in other words, body weight alone cannot be depended upon in determining the dose required for any particular patient.

A similar conclusion emerges from analysis of Figure 4 , in which the weightduration relationship has been depicted graphically. An important feature of this trace is the vertical scale of duration of action which is related to the number of cases based on the second scale on the extreme left. Since the resultant trace essentially represents a straight line progression without significant break, it can be

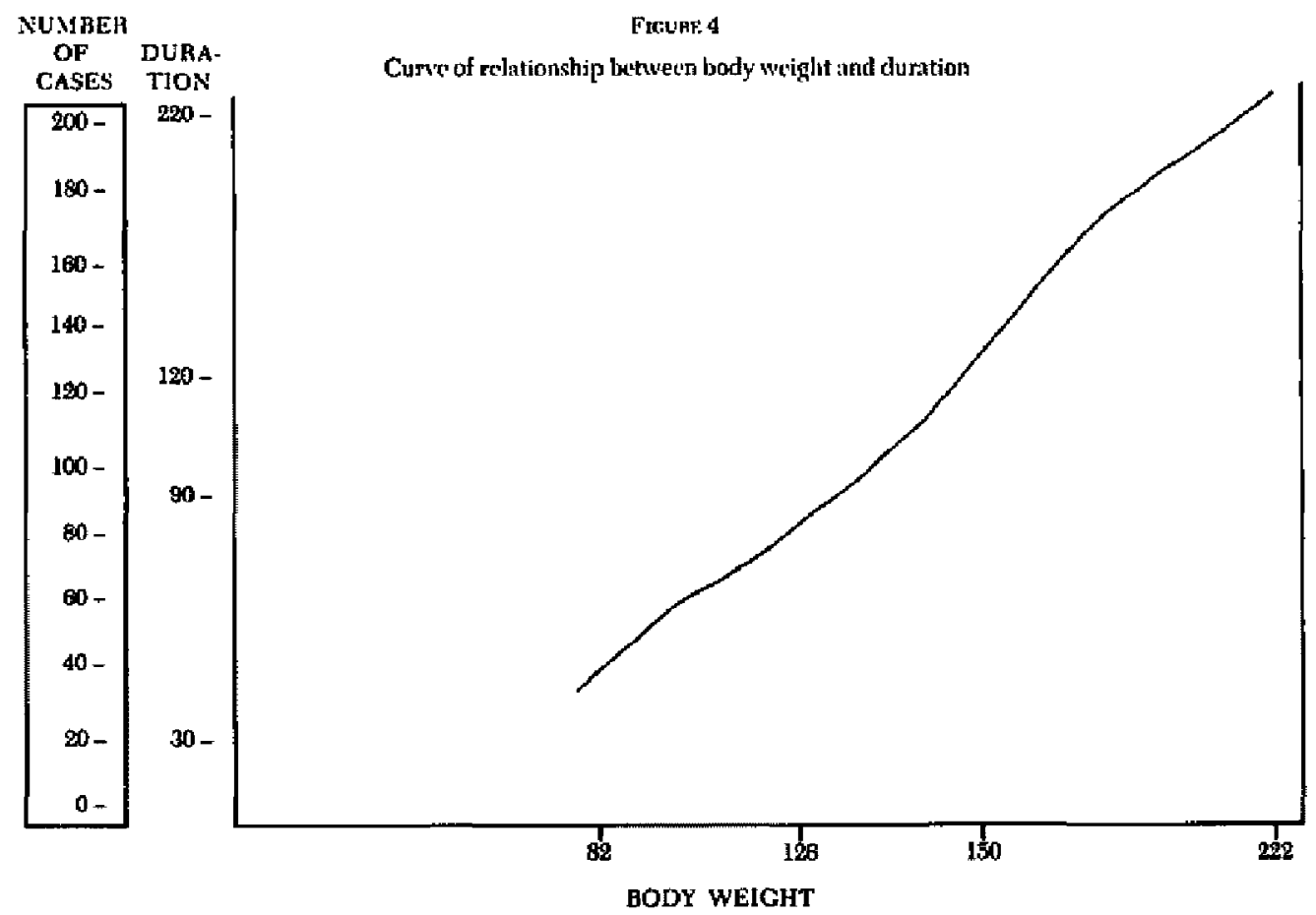


TABLE $\mathrm{V}$

Age/Duration ReLationship

\begin{tabular}{|c|c|c|c|c|c|}
\hline & \multicolumn{5}{|c|}{ Duration. } \\
\hline & & I & II & III & Total \\
\hline $\begin{array}{l}\text { AGE } \\
\text { (young) } \\
\text { (middleaged) } \\
\text { (old) }\end{array}$ & $\begin{array}{l}\text { II } \\
\text { III }\end{array}$ & $\begin{array}{l}22 \\
19 \\
22\end{array}$ & $\begin{array}{l}23 \\
25 \\
20\end{array}$ & $\begin{array}{l}20 \\
23 \\
24\end{array}$ & $\begin{array}{l}65 \\
67 \\
66\end{array}$ \\
\hline TotaL. & & 63 & 68 & 67 & 108 \\
\hline
\end{tabular}

concluded, on the basis of the special treatment of the time scale which has just been described, that weight of the patient is not sufficient to allow prediction of the duration of effect of the initial dose.

A fifth analysis deals with the relation between age and duration of action (Table V). All other factors again remaining constant, Table V shows the relationship between the age groups and the duration of the initial dose using the groupings previously established and listed in Table II. Analysis of this table reveals that there is no direct relationship between age and duration of initial dose. Consequently, age by itself does not have any effect on the duration of the initial dose. This means that age itself cannot be depended upon to predict the initial dose required for each case.

The same descriptions and conclusions which have been applied to the graphic representation of the weight-duration relationship also apply to the relation between age and duration (Figure 5). Again the straight line progression invites the conclusion that age alone is not a sufficient factor to permit a prediction of the duration of the initial dose.

Finally, the effect of the dosage and the weight on the duration was analyzed and is listed in Table VI.

From perusal of this table it emerges that

29 patients received a dose of approximately $2 \mathrm{mg}$

101 patients received a dose of approximately $3 \mathrm{mg}$, and

68 patients received a dose of $4 \mathrm{mg}$ and more.

It further becomes clear that, whatever the dose, in 30 per cent of the cases (60/198) the effect lasted less than 90 minutes, in 36 per cent the effect lasted between 90 and 120 minutes and in 34 per cent it lasted more than 120 minutes.

Among the 30 per cent on which the effect lasted less than 90 minutes, 64 per cent received a dose of $3 \mathrm{mg}$ and 18.5 per cent received a dose of 2 to $4 \mathrm{mg}$ each. Between 90 and 120 minutes, 54 per cent received a dose of $3 \mathrm{mg}$ whereas 13 per cent received a dose of $2 \mathrm{mg}$ and 33 per cent received a dose of $4 \mathrm{mg}$ and more.

Those patients who had received $2 \mathrm{mg}$ represent 18.5 per cent of those which lasted 30 to 89 minutes and 13 per cent of each the 90 to 119 and the 120 to 220 minutes.

Those who had received a dose of $3 \mathrm{mg}$ comprise 63 per cent of duration of Group I, 54 per cent of Group II and 38 per cent of Group III. 


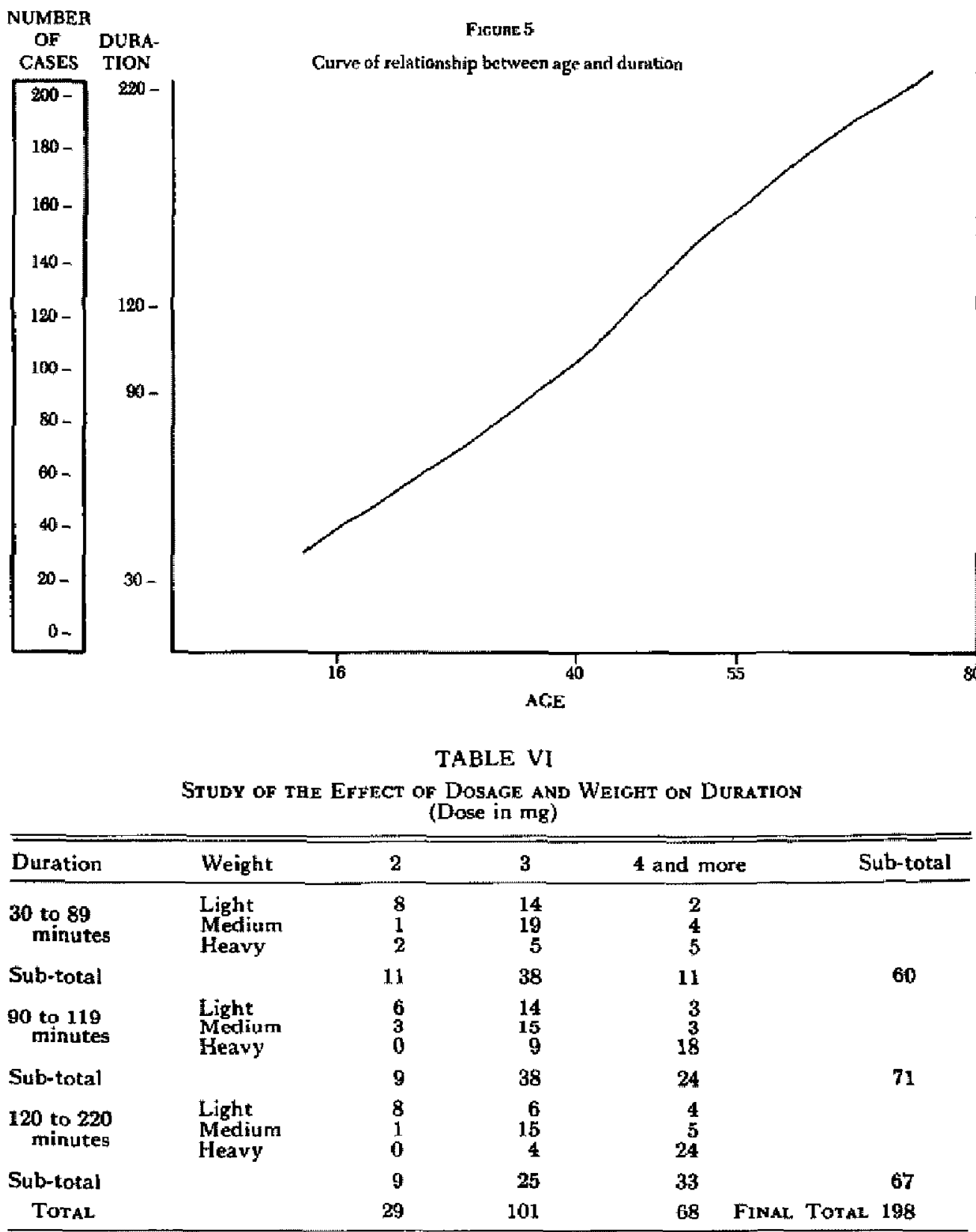

Those who had received a dose of $4 \mathrm{mg}$ and more comprise 18.5 per cent of Group I, 33 per cent of Group II and 49 per cent of Group III.

Doses of less than $4 \mathrm{mg}$ did not seem to have a direct effect on the duration of the initial dose. At least one factor other than weight intervenes for there are more individuals of normal weight than obese ones.

For doses of $4 \mathrm{mgs}$ or more there exists a direct relation between the dose of 
Pancuronium and body weight, between the dose and the duration of action of Pancuronium and between body weight and duration of action.

\section{SUMMARY}

Body weight and the dose of Pancuronium are two factors which influence the duration of its effect, but at least one other factor intervenes. A study of the regression of several factors on the variation of dosages confirms the conclusion, that age is the third factor which, in combination with weight and dose, determines duration of action of Pancuronium.

It is the association of these three factors which permits one to predict the duration of the initial dose, while each factor by itself alone cannot do so.

$\left.\left.\begin{array}{l}\text { Weight predicts up to } 25 \% \\ \begin{array}{l}\text { Dose predicts up to } 35 \% \\ \text { Age predicts up to } 10 \%\end{array}\end{array}\right\} 61 \%\right\} 71 \%$

It follows that a prediction taking into consideration only weight and dose is 61 per cent reliable, while the combination of all three factors constitutes a prediction of the initial dose which has a 71 per cent probability of being correct.

In order now to determine the total dose of Pancuronium required in any one particular instance it is still the interaction of these three factors which provides the most efficient method.

However the weight by itself could be used as a good criterion for the calculation of total dosage as it contributes 62 per cent to the prediction. The age of the patient and the length of the operation are also factors to be considered although they are of lesser importance, contributing only another 5 per cent and 16 per cent respectively to a total predictability of 83 per cent.

\section{CONCEUSTON}

This study of the use of Pancuronium in major abdominal operations in conjunction with a standard method of anaesthesia permits one to determine with some accuracy the appropriate dosages and the duration of the effect of Pancuronium in certain types of cases.

\section{RÉSUMÉ}

Cette étude clinique vise à étudier les conditions d'utilisation du Pancuronium en chirurgie abdominale majeure et ceci en présence d'une méthode d'anesthésie bien spécifique. On veut donc connaitre davantage les dosages appropriés de Pancturonium et la durée d'effet de ce produit sur certains types de cas.

En conclusion, le poids et la dose sont deux facteurs qui influencent la durée d'effet mais au moins un autre facteur intervient. Une étude de la régression de plusieurs facteurs sur une variable dépendante vient confirmer ces conclusions. En effet, le poids, la dose et l'âge sont les trois (3) principaux facteurs qui déterminent la durée.

C'est l'association de ces trois facteurs qui pernet de prédire la durée d'effet de 
la dose initiale. Chacun en particulier ne constitue pas un bon prédicteur de la durée. Ainsi d'après l'analyse statistique (Re: Tableau 14)

Le poids prédit $\$ 25 \%$

La dose prédit à $36 \%$

L’âge prédit à $10 \%$

Le poids et la dose ensemble prédisent à 61 pour cent ce qui dans les circonstances est très valable. L'association des trois facteurs constitue un bon prédicateur a 71 pour cent.

Comme prédicteur de la dose, c'est encore une interaction de trois facteurs qui a te plus d'efficacité.

Cependent, le poids à lui seul contribue à 62 pour cent de la prédiction, c'està-dire qu'il peut servir de base comme critère de la dose à administrer (Re: Tableau 15). L'âge du patient et le temps d'opération sont eux aussi des facteurs à considérer quoique de moindre importance ( 5 pour cent et 16 pour cent).

Si les trois facteurs sont considérés ensemble, on peut déterminer avec une précision de 83 pour cent la dose adéquate (certains critères étant fixés).

\section{BIBLIOGAAPHY}

BAmD, W.L.M. Report on clinical experience with Pancuronium bromide. Research Release Report. No. 32 N.V. Organon OSS.

Bamd, W.L.M. Some clinical experiences with a new neuromuscular blocking drug, Pancuronium bromide, Favulon, NA 97. Inish 3. Med. Sc., 1: 559-563, Dec. 1968.

BAmd, W.L.M. \& Rew, A.M. The neuromuscular blocking properties of a new steroid compound, Pancuronium bromide. Brit. 3. Anaesth., 39: 775-780, Oct. 1967.

BonTa, I.L, Tentative experiments on cardiovascular effects of NA 97, a neuromuscular blocking steraid. Research Release Report Mo. 35. N.V. Organon OSS.

Bonta, I,L, Goonissen, E.M., \& Derux, F.X. Pharmacological interaction between Pancuronium bromide and anaesthetics. Eur. 3. Pharmacol, 4: 83-90, 1968.

Bucketr, W.R. The pharmacology of Pancuronium bromide; a new non-depolarizing neuromuscular blocking agent. Irish 3. Med, Sc., 1 : 565-568, Dec. 1968.

Bucrett, W.R., Marjonimanks, C.E.B., Marwick, F.A., \& Monton, M.B. The pharmacology of Pancuronium bromide, a new potent steroidal neuromuscular blocking agent. Br. J. Pharmac. Chemother, 32: 671-682, 1968.

Crul, J.F. Studies on new steroid relaxants. 4th World Congress of Anaesthesiologists, 1968. Excerpta Medica, 41B.

Fastrier, Z. \& AcostoN, S. A new neuromuscular blocking agent, Pancuronium bromide (Pavulon") Clinical trials J.; 7: 254-260, Feb. 1970.

Komesanof F, David Further clinical studies on Pancuronium bromide. 1. A comparison with other non-depolarizing muscle relaxants. Med. J. Aus. 2: 494-497, Sept. 12, 1970.

Komesarorf, David Further clinical studies on Pancuronium bromide. 2. A study of the effects on the blood pressture and pulse rate. Med. J. Aust. 2: 497-499, Sept. 12, 1970.

Komitsanofr, Davio \& Fater, J.E. Pancuronium bromide: a new non-depolarizing muscle relaxant. The Med. J. Aust., 908-911, May 1969.

McDowel. , S.A. \& Cinfixe, R.S.J. A clinical comparison of Pancuronium and D-Tubocurarine. Anaesthesia, 24: 58I-590, Oct. 1969.

Smiti, G., Procton, D.W. \& SpEnce, A.A. A comparison of some cardiovascular effects of tubocurarine and Pancuronium in dogs. Brit. J. Angesth.; 42: 923-927, 1970.

Trndall, W.J. \& Buckert, W.R. A review of the clinical properties of Pancuronium bromide and its advantages in comparison with other curariform agents in current use. Research Release Report No. 42. N.V. Organon OSS. 